CASE REPORT

\title{
External ophthalmomyiasis by Oestrus ovis larvae: A Rare Case Report
}

\author{
B. M. Shanker Venkatesh, P. Ganga Bhavani
}

Department of Microbiology, Sarojini Devi Eye Hospital, Hyderabad, India

\begin{abstract}
Myiasis is defined as the infestation of live vertebrates (humans and animals) with dipterous larvae. The Prevalence of Myiasis of different organs has been reported from various regions in the world. Ophthalmomyiasis, or oculomyiasis, is the infestation of any anatomic structure of the eye by the larvae. In the Indian population, reporting of ocular myiasis cases has been very few, and in this part of the country, it is infrequent.

Hereby we present a human case of External Ophthalmomyiasis caused by the larvae of a sheep bot fly, Oestrus ovis, for the first time from Sarojini Devi Eye Hospital, a tertiary eye care hospital in Hyderabad city in the Telangana State of India. J Microbiol Infect Dis 2021; 11(3):159-161.
\end{abstract}

Keywords: Ophthalmomyiasis, Oestrus ovis, Uniocular conjunctivitis

\section{INTRODUCTION}

Myiasis is defined as the infestation of larvae on human and animal tissues [1]. Although myiasis in humans is generally rare, members of the Oestridae (Diptera) may produce the infection in countries where the standard of hygiene is low, and the other contributing factors include areas with numerous flies, old age, severe ill health, unsanitary conditions, and the presence of exposed, ulcerative and devitalized tissue. People exposed to animals or with a degree of immobility in these areas are at higher risk

Though the most common site of infection is damaged skin, it is also less commonly seen in the throat, nose, eyes, and urogenital tract [2].

Ophthalmomyiasis is the infection of the eye caused by larvae. This group is further subclassified into ophthalmomyiasis externa or superficial (affecting the lids and adnexa, conjunctiva, and ocular surface) and ophthalmomyiasis interna and Orbital myiasis, or "ophtalmomyiase profonde" (a French term meaning profound), which includes palpebral or periocular infestation with intraocular myiasis [3].

Ophthalmomyiasis is known to occur more commonly in the spring and summer seasons
[4]. There are reports of Oestrus ovis causing orbital infections from different parts of the world. It is most commonly found in Tropical rural zones with warm weather, like Central America, the southern United States, Africa, and southern Asia [5]. Ophthalmomyiasis has also been reported in various parts of the world like Oman, Russia, Africa, Serbia, Iran, Afghanistan, and Libya [6].

Though rare in India, this condition has been reported from North India and some places in Andhra Pradesh, Tamil Nadu, and some parts of Karnataka [7]. However, its incidence in Telangana state has not been reported at least in the last ten years.

We, therefore, present this case to highlight the fact that larval conjunctivitis (external ophthalmomyiasis by Oestrus ovis) though a rare manifestation, can be one of the causes of uniocular conjunctivitis, especially in the spring and summer season and whose timely diagnosis and treatment will prevent complications.

\section{CASE}

An 18-year old male student applied to the Outpatient Department of Sarojini Devi Eye Hospital, a tertiary eye care hospital in Hyderabad, on 23/02/2021, with complaints of 
redness and foreign body sensation in the left eye for a day. He gave a history of something falling in his eye while he was resting below a tree in the college, and there was no significant history of ocular or medical problems. On slit-lamp examination, he had edema of the lid and conjunctival congestion. Further examination revealed the presence of rapidly moving tiny larvae, $1-2 \mathrm{~mm}$ in size with dark heads, crawling over the inferior part of conjunctiva, fornix, and cornea

The extraocular movements were normal. The patient's vision was $6 / 6$ in both eyes. On examination, the right eye was normal. After applying topical anesthesia, three organisms were removed with the help of sterile cotton swab sticks and fine plain forceps. The larvae (three in number) were placed in normal saline and were later mounted on a glass slide and sent to the Microbiology Department for further investigation and identification.

On microscopic examination, the specimens were identified as the first stage larvae of Oestrus ovis (the sheep nasal botfly). They were identified by their typical features like the spindle-shaped segmented body with intersegmental spine bands along with a pair of dark brown, sharp, oral hooks and tufts of numerous hooks at the anterior end (Figure 1). The posterior spiracles were found in the eighth segment.

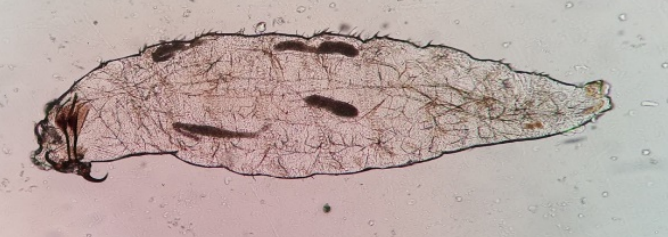

Figure 1. Wet mount test showing spindle shaped body.

\section{DISCUSSION}

As per the literature incidence of external ophthalmomyiasis is rare in humans. Though $O$. ovis is the major causative fly involved in ophthalmomyiasis, other lesser common fly species include Calliphora, Lucilla, Sarcophaga, Gasterophilus, Hypoderma, Musca, Callitroga, Cuterebra Dermatobia, Chrysomya, Wohlfahrtia, Oedemagena, and Cochliomyia [8]. Oestrus ovis, commonly known as sheep nasal botfly, is a worldwide parasite that infests the nasal cavity and paranasal sinuses of sheep, goats, cattle, and horses [9].

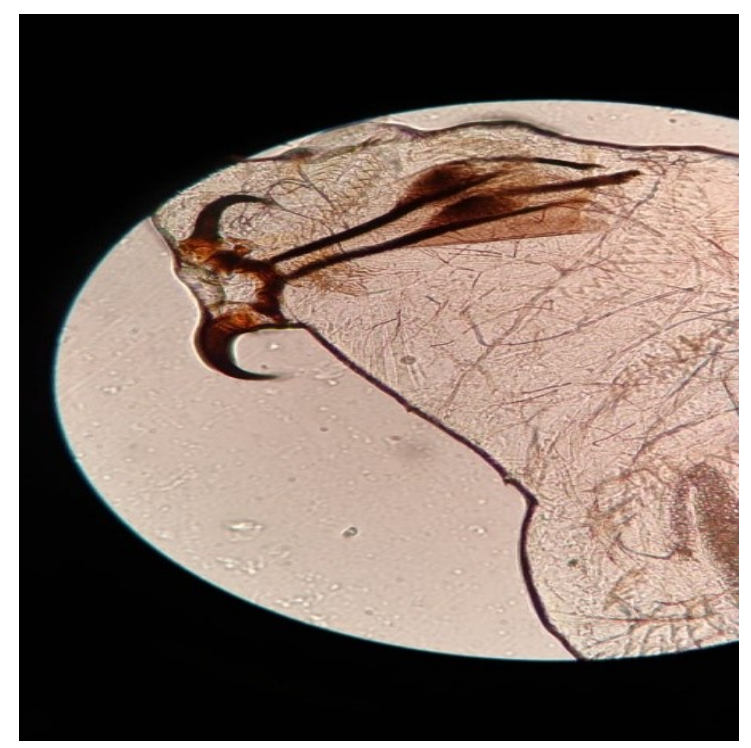

Figure 2. Wet mount test showing brown colored oral hooks.

It is an obligate parasite, and the female fly is large dark gray with dark spots on the dorsum of the thorax and abdomen and is covered by a moderate amount of light brown hair [10]. The gravid female flies dart near the eyes or nostrils, the conjunctiva, on the lip, and in the mouth of the usual hosts like sheep, cattle, and horse and eject a stream of first-instar larvae, which mature in the mucus membrane [11] The larvae undergo maturation in three stages, and after several months, third stage larva sneeze out and pupate in soil [12]. Man acts as an accidental fortuitous host, and in them, they hold on to mucus membrane through their pointed hooks but do not penetrate any more profound and remain confined to the conjunctiva [12]. In general, $O$. ovis larvae do not survive beyond ten days in human hosts and die off. The larva is translucent and not easily visible to the unaided eye. It might be detected only with a slit lamp examination when they start crawling away from light [13]. They have dark claw-like hooks with which they attach onto the skin and mucous membrane of the conjunctiva [10]

External ophthalmomyiasis clinically manifests as acute catarrhal conjunctivitis that can cause a great deal of irritation, lacrimation, pain, inflammation and may lead to secondary bacterial infection causing acute mucopurulent conjunctivitis [13]. However, they are also equipped with oral hooks and spines (Figures 1 and 2) and can burrow into the lids or 
penetrate the globe through the sclera into the eye's inner structures, causing internal ophthalmomyiasis. The consequent panuveitis is often severe, and the visual prognosis is poor.

\section{Conclusion}

In developing countries like India, where the general standard of hygiene is low, and there are a large number of flies around, especially during the spring and summer seasons, ophthalmologists should consider larval conjunctivitis (external ophthalmomyiasis) as one of the causes of uniocular conjunctivitis, as it may present with similar features of conjunctivitis of other causes like redness, pain, watering and discharge and which might easily be misdiagnosed.

In addition to this, the larva is translucent and may be easily missed, which might lead to vision-threatening complications like acute iridocyclitis or endophthalmitis secondary to ophthalmomyiasis interna. Debilitated older people and poorly nourished children are particularly susceptible to internal ophthalmomyiasis. In severe cases, particularly in tropical countries, the maggots eat tissues and convert the whole orbit into a crawling pit [14]. Larvae of $O$. ovis do not secrete proteolytic enzymes, and as such, they cannot penetrate through intact cornea and sclera, but studies have shown that they are known to cause keratitis and kerato-uveitis. We, therefore, advise the Ophthalmologists not to consider Ophthalmomyiasis externa caused by $O$. ovis as a benign condition and should therefore be treated promptly to prevent serious complications such as corneal ulcer, decreased vision, and invasion into the eye globe causing endophthalmitis, iridocyclitis, and even blindness which has been reported in the past.

\section{ACKNOWLEDGMENTS}

Declaration of Conflicting Interests: The authors declare that they have no conflict of interest.

\section{Funding: Not applicable}

\section{REFERENCES}

1. White GB. Myiasis. In: Cook GC, Zumla A, editors. Manson's Tropical Diseases. 22nd ed., Ch. 88. London, UK: WB Saunders Publishers; 1996. p. 15261532.
2. Amr ZS, Amr BA, Abo-Shehada MN. Ophthalmomyiasis externa caused by Oestrus ovis L. in the Ajloun area of northern Jordan. Ann Trop Med Parasitol 1993; 87:259-262.

3. Thompson JH, Knutson LV, Culp OS. Larva of Scenopinus sp (Diptera: Scenopinidae) causing human urogenital myiasis. Mayo Clin Proc 1970; 45:597-601.

4. Masoodi M, Hosseini K. External Ophthalmomyiasis caused by sheep botfly (Oestrus ovis) larva: A report of 8 cases. Archiv Iranian Med 2004; 7(2):136-139.

5. Smillie I, Gubbi PKS, Cocks HC. Nasal and ophthalmomyiasis: case report. J Laryngol Otol 2010; 124:934-935.

6. Victor R, Bhargva K. Ophthalmomyiasis in Oman: a case report and comments. Wilderness Environ Med 1998; 9:32-35.

7. Rao S, Radhakrishnasetty $\mathrm{N}$, Chadalavada $\mathrm{H}$, Hiremath C. External ophthalmomyiasis by Oestrus ovis: A case report from Davangere. J Lab Physicians 2018; 10(01):116-117.

8. Khurana S, Biswal M, Bhatti HS, et al. Ophthalmomyiasis: Three cases from North India. Indian J Med Microbiol 2010; 28:257 261.

9. Özyol P, Özyol E, Sankur F. External ophthalmomyiasis: A case series and review of ophthalmomyiasis in Turkey. Int Ophthalmol 2016; 36:887

10. Padmaja N, Chaitanya K. 2019. A Rare Case of Ophthalmomyiasis Externa in Kims Hospital, Amalapuram. Int J Curr Microbiol App Sci 2019; 8 (07): 809-812.

11. Pandey A, Madan M, Asthana AK, Das A, Kumar S, Jain K. External Ophthalmomyiasis Caused by Oestrus ovis: A Rare Case Report from India. Korean J Parasitol 2009; 47(1): 57-59.

12. Cameron JA, Shoukrey NM, al-Garni AA. Conjunctival ophthalmomyiasis caused by the sheep nasal botfly (Oestrus ovis). Am J Ophthalmol 1991; 112:331-234

13 Hennessy DJ, Sherrill JW, Binder PS. External ophthalmomyiasis caused by Oestrus ovis. Am J Ophthalmol 1977; 84: 802-805.

14. Khataminia G, Aghajanzadeh R, Vazirianzadeh B, Rahdar M. Orbital Myasis. Case Reports J Ophthalmic Vis Res 2011; 6(3):199-203. 